\title{
Investigating the biomechanical function of the plate-type external fixator in the treatment of tibial fractures: a biomechanical study
}

\author{
Di Shi ${ }^{1}$, Kaiyuan Liu'², Haomeng Zhang ${ }^{1}$, Xinli Wang ${ }^{1}$, Guochen $\mathrm{Li}^{1}$ and Lianhe Zheng ${ }^{1 *}$ (D)
}

\begin{abstract}
Background: The design of an external fixator with the optimal biomechanical function and the lowest profile has been highly pursued, as fracture healing is dependent on the stability and durability of fixation, and a low profile is more desired by patients. The plate-type external fixator, a novel prototype of an external tibial fixation device, is a low profile construct. However, its biomechanical properties remain unclear. The objective of this study was to investigate the stiffness and strength of the plate-type external fixator and the unilateral external fixator. We hypothesized that the plate-type external fixator could provide higher stiffness while retaining sufficient strength.
\end{abstract}

Methods: Fifty-four cadaver tibias underwent a standardized midshaft osteotomy to create a fracture gap model to simulate a comminuted diaphyseal fracture. All specimens were randomly divided into three groups of eighteen specimens each and stabilized with either a unilateral external fixator or two configurations of the plate-type external fixator. Six specimens of each configuration were tested to determine fixation stiffness in axial compression, four-point bending, and torsion, respectively. Afterwards, dynamic loading until failure was performed in each loading mode to determine the construct strength and failure mode.

Results: The plate-type external fixator provided higher stiffness and strength than the traditional unilateral external fixator. The highest biomechanics were observed for the classical plate-type external fixator, closely followed by the extended plate-type external fixator.

Conclusions: The plate-type external fixator is stiffer and stronger than the traditional unilateral external fixator under axial compression, four-point bending and torsion loading conditions.

Keywords: Tibial fracture, Plate-type external fixator, Axial compression, Four-point bending, Torsion

\section{Background}

Traditionally, external fixators have been selected as osteosynthesis devices for the treatment of open tibial fractures and certain closed tibial fractures with severe injury to soft tissue [1,2]. External fixation devices provide a promising and satisfactory alternative for better soft tissue care and for preserving periosteal perfusion to the regions of fracture [3, 4]. They can also be selected for use as interim or definite devices of fracture fixation

\footnotetext{
* Correspondence: Xiaowandou@163.com

${ }^{1}$ Department of Orthopedics, the Second Affiliated Hospital of Air Force

Medical University, Xi'an 710038, Shaanxi, China

Full list of author information is available at the end of the article
}

[4]. However, previous studies have demonstrated that the stiffness of a fixation device is a principal determinant of interfragmentary movement, which has a significant effect on the mechanism and progression of fracture healing $[5,6]$. Excessive interfragmentary movement, due to insufficient stiffness of external fixators, can result in deficient callus formation, eventually leading to delayed union or even nonunion with ultimate implant failure [7-9]. Meanwhile, an external fixator with high strength can contribute to durable fixation to allow progressive functional training [10]. In addition, the large profile of the implants, which tends to confer inconvenience to patients during dressing and

(c) The Author(s). 2020 Open Access This article is distributed under the terms of the Creative Commons Attribution 4.0 International License (http://creativecommons.org/licenses/by/4.0/), which permits unrestricted use, distribution, and reproduction in any medium, provided you give appropriate credit to the original author(s) and the source, provide a link to the Creative Commons license, and indicate if changes were made. The Creative Commons Public Domain Dedication waiver (http://creativecommons.org/publicdomain/zero/1.0/) applies to the data made available in this article, unless otherwise stated. 
ambulation, has led to low acceptance of the implants among patients $[11,12]$.

External fixators used in present clinical practice have various limitations, including insufficient fixation stiffness and strength, leading to poor healing, or high construct profiles, resulting in nonpatient friendly physical burden [13-17]. It is therefore essential to design a novel prototype of an external fixator for tibial fracture to increase rigidity and strength while reducing the profile of the fixation constructs. Our research group designed the plate-type external fixator, a novel prototype of an external tibial fixation device, with a lower profile than traditional unilateral external fixators, which was designed for greater construct stability and durability to treat open tibial fractures and certain closed tibial fractures with severe injury to soft tissue, and we are the first group worldwide to describe such a prototype. In addition, the length of the novel fixator can be adjusted for people of different heights.

Since the biomechanical function of plate-type external fixators remains unclear, this study was performed to investigate the biomechanical parameters of a novel external fixator by comparing with the unilateral external fixator $[4,6,18]$. We hypothesized that the plate-type external fixator would provide higher fixation stability and durability than traditional external tibial fixation devices.

\section{Methods}

\section{Fracture model}

A total of fifty-four fresh and unembalmed tibias were selected from fifty-four voluntarily donated adult male cadavers (Department of Anatomy, Air Force Medical University, Xi'an, China) between the ages of 18 and 50 . The average length of the selected tibias was $340 \mathrm{~mm}$ (range from $310 \mathrm{~mm}$ to $375 \mathrm{~mm}$ ). All selected tibias specimens were examined for bone mineral density, and osteoporosis was ruled out by means of dual energy Xray absorptiometry (LUNAR IDAX, GE Inc., Boston, Massachusetts, USA). The tibias were then cleaned of any soft tissues for use in this study. T-scores were selected to represent the values of bone mineral density.

The novel external tibial fixation device prototype, namely, the plate-type external fixator, consists of a proximal tibial fixation lath with a transverse slat at the proximal end and a distal tibial fixation lath with a transverse slat at the distal end. The distal end of the proximal fixation slat is equipped with a slot, and the proximal end of the distal fixation slat can be inserted into the slot and can slide along lath to adjust the length of the fixator to accommodate various lengths of the human lower limb. In addition, the tibial fixation laths and the transverse slats are both equipped with locking screw holes, and all the screws used are fully threaded self-tapping locking screws (Fig. 1). With a lower profile than the traditional unilateral external fixator, the novel external tibial fixator, designed to match perfectly with the crus, is expected to make it easier to adjust the plate close to the bone surface. For this study, we lengthened the plate-type external fixator by $30 \mathrm{~mm}$, namely, twofold the hole spacing, to clarify whether the extended plate-type external fixator could also provide sufficient stiffness and strength.

The fifty-four tibias were randomly divided into three groups of eighteen specimens each for fixation by a classical plate-type external fixator (CPF), an extended plate-type external fixator (EPF) or the the unilateral external fixator (UEF). Subsequently, the eighteen specimens of each configuration group were randomly divided into three groups of six specimens each for axial compression, four-point bending, and torsion testing, respectively.

A standardized midshaft osteotomy by means of an oscillating saw was performed in all tibias to create a 20 $\mathrm{mm}$ fracture gap, measured with the aid of a Vernier caliper, to simulate a comminuted tibial shaft fracture and to ensure no contact between both ends of the fracture. Eighteen specimens were stabilized with a 13-hole stainless steel CPF (300 mm in length, $21 \mathrm{~mm}$ in width, $10 \mathrm{~mm}$ in thickness, Kangding Medical Alliance Co., Ltd., Shanghai, China), with three $5 \mathrm{~mm}$ diameter stainless steel locking screws placed proximally in the first, third and fifth locking holes and three $5 \mathrm{~mm}$ diameter stainless steel locking screws placed distally in the ninth, eleventh and thirteenth locking holes. Another eighteen specimens were stabilized with a 15-hole stainless steel extended plate-type external fixator $(330 \mathrm{~mm}$ in length, $21 \mathrm{~mm}$ in width proximally and $16 \mathrm{~mm}$ in width distally, $10 \mathrm{~mm}$ in thickness proximally and $5 \mathrm{~mm}$ in thickness

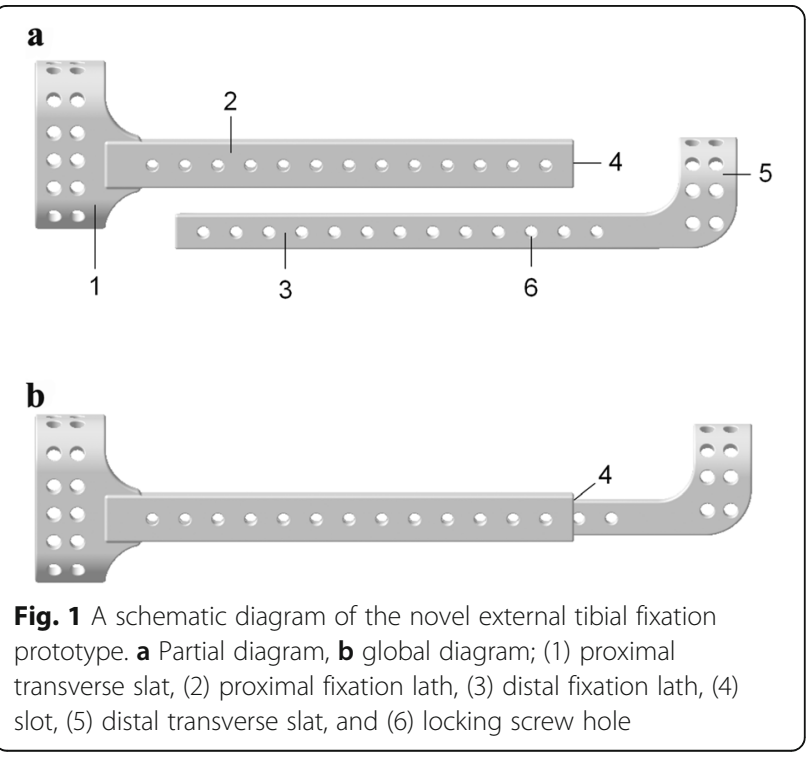


distally, Kangding Medical Alliance Co., Ltd., Shanghai, China), with three $5 \mathrm{~mm}$ diameter stainless steel locking screws placed proximally in the second, fourth and sixth locking holes and three $5 \mathrm{~mm}$ diameter stainless steel locking screws placed distally in the tenth, twelfth and fourteenth locking holes. Both plate-type external fixators have a hole spacing of $15 \mathrm{~mm}$.

The final eighteen specimens were stabilized with a stainless steel UEF (Kangding Medical Alliance Co., Ltd., Shanghai, China) as the control group. Three stainless steel half-pins ( $5 \mathrm{~mm}$ in diameter) were fixed per fragment and linked with pin clamps to a stainless steel rod (300 $\mathrm{mm}$ in length, $11 \mathrm{~mm}$ in diameter). The positions of the half-pins corresponded to the proximal locking screws of the CPF in the first, third and fifth holes and to the distal locking screws in the ninth, eleventh and thirteenth holes.

The choice of three locking screws/half-pins per fracture fragment in our study adhered to the $\mathrm{AO}$ principles of external fixation that a minimum of three screws were needed to achieve stable fixation on either fragment of the fracture. The $\mathrm{AO}$ recommended having a screw near and a screw far from the fracture end in both fragments; however, for the sake of comparison, the most distant screws were inserted into the second and fourteenth locking holes in the extended plate-type external fixator group instead of into the first and fifteenth locking holes, so the same three locking screws/half-pins positions were used in both fragments of the fracture among the three fracture fixation configuration groups. We acknowledge that this represents a limitation of our study, as the adjustment of the locking screws may influence the fixation stiffness of the extended plate-type external fixator.

The offset distance was restricted to $15 \mathrm{~mm}$ between the bone surface and the external plates/rods to allow the swelling of soft tissue without disturbance of the configuration and to provide sufficient space for postoperative care. We chose an offset of $15 \mathrm{~mm}$ instead of 20 $\mathrm{mm}$ or $30 \mathrm{~mm}$ for the purpose of increasing the fixation stability of the configuration to prevent excessive interfragmentary movements $[4,19,20]$. The inner locking screws/half-pins were inserted at a distance of $20 \mathrm{~mm}$ from the fracture end. The locking screws/half-pins used were long enough to ensure adequate purchase of the bilateral cortex.

\section{Mechanical testing}

The proximal and distal ends of all the fracture fixation configurations were potted in polymethylmethacrylate for mechanical testing (Fig. 2) [6]. Subsequently, the bone-implant constructs were mounted in the testing machine with a customized clamp. The classical platetype external fixation constructs, the extended plate-type

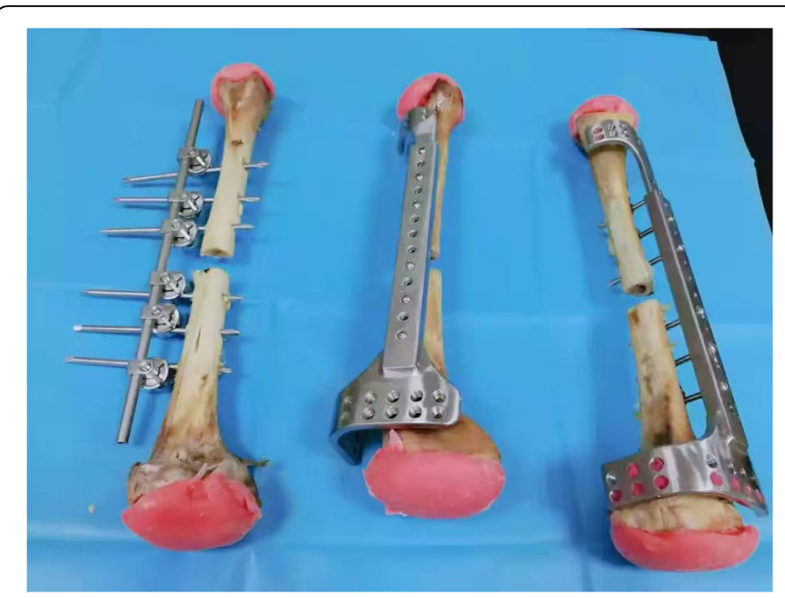

Fig. 2 A photograph of the fixation configurations potted in polymethylmethacrylate. Left: unilateral external fixator; middle: classical plate-type external fixator; right: extended plate-type external fixator.

external fixation constructs and the unilateral external fixation constructs were tested to determine the fixation stiffness under three loading conditions (axial compression, four-point bending and torsion) (Fig. 3) $[6,21]$. The relative displacements at the fracture site were recorded on a computer to calculate the stiffness of the configuration. Subsequently, the three constructs underwent dynamic loading until failure under each loading mode to determine the construct strength and the failure modes. Construct strength was defined as the peak load at the moment of construct failure during progressive dynamic loading to failure under each loading mode. Configuration failure was defined either by catastrophic fracture or by nonrecoverable deformation in the region of fracture, whichever occurred first $[5,22-$ 24].

\section{Axial compression test}

Both ends of the constructs were mounted with the use of a customized axial compression clamp in the Zwick/ Roell-Z005 electronic materials testing machine (Ulm, Germany) (Fig. 3a). The applied loading was gradually increased from $0 \mathrm{~N}$ to a maximum load of $700 \mathrm{~N}$, corresponding to the weight of a $70 \mathrm{~kg}$ person during a onelegged stance [25], at a rate of $0.1 \mathrm{~mm} / \mathrm{s}$ for six cycles. The interfragmentary displacements at the fracture site were determined by means of laser displacement sensors (LK-G10, KEYENCE Inc., JAPAN). Axial compression stiffness was determined by dividing the axial load values by the vertical displacement values and was expressed in $\mathrm{N} / \mathrm{mm}$.

After the static test, sinusoidal loading with a constant load amplitude was applied for each construct. Every 100 loading cycles, the load amplitude was increased 

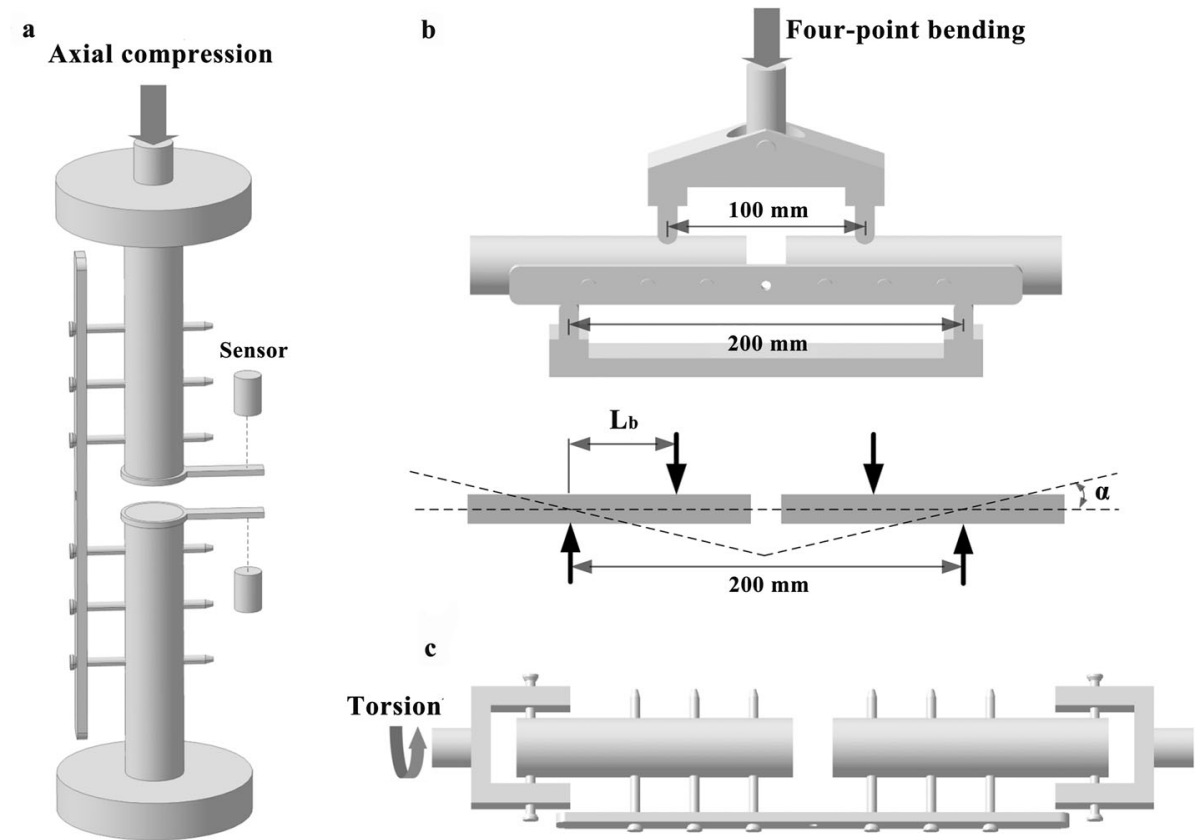

Fig. 3 Schematic graphs of the construct stiffness evaluated under three loading conditions. a axial compression, $\mathbf{b}$ four-point bending, and $\mathbf{c}$ torsion. Lb, bending length; a, bending angle

stepwise by $100 \mathrm{~N}$ until configuration failure occurred, while preloading was applied to $50 \mathrm{~N}$ to ensure that construct failure occurred within a reasonable number of loading cycles $(<10,000)$ by increasing the load stepwise to failure $[5,21]$.

\section{Four-point bending test}

The constructs were placed in turn by means of a customized bending clamp on a Zwick/Roell-Z005 electronic materials testing machine (Ulm, Germany) (Fig. $3 \mathrm{~b})$. The bending moment was calculated by multiplying the bending force by the bending length. The distance between the lower supports was set to $200 \mathrm{~mm}$, while the upper supports were separated by $100 \mathrm{~mm}$. The bending length, defined as the distance between the upper and lower supports on either side of the fracture, was set to $50 \mathrm{~mm}$. The bending force applied was constantly increased up to $400 \mathrm{~N}$, corresponding to a bending moment of $20 \mathrm{Nm}$, at a rate of $1 \mathrm{~mm} / \mathrm{min}$. The bending stiffness was calculated by dividing the bending moment by the bending angle and was expressed in $\mathrm{Nm} / \mathrm{deg}[26,27]$. Afterwards, sinusoidal loading with a constant amplitude was applied for each configuration. The load amplitude was increased gradually every 100 loading cycles by $1 \mathrm{Nm}$ until configuration failure occurred, while the preload was applied to $1 \mathrm{Nm}$ [5].

\section{Torsion test}

The torsional testing was performed by using a CTS-500 microcomputer controlled torsion test machine
(Hualong Testing Instrument Co., Ltd., Shanghai, China) equipped with a custom-made torsional clamp, with the proximal and distal ends of the constructs being rigidly clamped by means of the clamp (Fig. 3c). The implemented torque was constantly increased from $0 \mathrm{Nm}$ to $10 \mathrm{Nm}$ at a rate of $0.1 \mathrm{deg} / \mathrm{s}$ for six cycles. Torsional stiffness was obtained by dividing the torque value by the relative rotation value and was expressed in $\mathrm{Nm} / \mathrm{deg}$. Subsequently, sinusoidal loading with a constant amplitude was applied for each configuration. The load amplitude was increased every 100 loading cycles in steps of $1 \mathrm{Nm}$ until construct failure occurred, while the preload was adjusted to $1 \mathrm{Nm}[5]$.

\section{Statistical analysis}

The collected data were statistically analyzed with SPSS 23.0 software (SPSS, Chicago, Illinois, USA). First, the results were tested for normality and homogeneity of variance. When a normal distribution and homogeneity of variance were found, the data were analyzed by means of one-way analysis of variance to determine the significance of differences in the means among the three groups. The LSD test was used for post hoc testing, if necessary. A $p<0.05$ was considered statistically significant.

\section{Results}

Age and bone mineral density

The mean age was similar among the CPF group (33.0 years), the EPF group (31.0 years) and the UEF group 
(35.5 years). One-way analysis of variance demonstrated that there was no significant difference $(F=0.311, p=$ $0.737)$ among the three fixation groups. The results are displayed in Table 1.

There was also no significant difference $(F=0.100, p=$ $0.905)$ in the mean T-score among the CPF group ($0.81)$, the EPF group $(-0.84)$, and the UEF group ($0.83)$. Table 1 displays the results. Since the mean Tscore values of the three fixation groups were all greater than -1 , we can conclude that all the specimens were normal bone and excluded of osteoporosis.

\section{Construct stiffness}

One-way analysis of variance demonstrated that the mean axial stiffness was significantly $(F=24.642, p<0.0001)$ different among the CPF group $(1898.8 \mathrm{~N} / \mathrm{mm})$, the EPF group $(1715.8 \mathrm{~N} / \mathrm{mm})$, and the UEF group $(1157.8 \mathrm{~N} / \mathrm{mm})$. The axial stiffness parameters of the three groups are displayed in the chart in Fig. 4a. The LSD test revealed that the axial stiffness of the CPF group was significantly $(p<$ 0.0001 ) higher than that of the UEF group by 0.64 . The axial parameter of the EPF group was also significantly $(p<$ 0.0001 ) higher than that of the UEF group by 0.48 .

There was a significant $(F=17.365, p<0.0001)$ difference in the mean four-point bending stiffness among the CPF group (26.7 Nm/deg), the EPF group ( $24.1 \mathrm{Nm} / \mathrm{deg})$, and the UEF group $(15.0 \mathrm{Nm} / \mathrm{deg})$. The chart in Fig. $4 \mathrm{~b}$ shows these values. The post hoc LSD tests were performed for pairwise comparisons, which revealed that the bending stiffness of the CPF group was significantly $(p<$ 0.0001 ) greater than that of the UEF group by $78 \%$. The stiffness value of the EPF group was also significantly ( $p=$ 0.001 ) greater than that of the UEF group by $61 \%$.

One-way ANOVA revealed significant $(F=130.824, p<$ $0.0001)$ differences in mean torsional stiffness among the CPF group ( $3.0 \mathrm{Nm} / \mathrm{deg})$, the EPF group $(2.6 \mathrm{Nm} / \mathrm{deg})$, and the UEF group $(1.3 \mathrm{Nm} / \mathrm{deg})$. The results are displayed in Fig. 4c. The subsequent LSD test demonstrated that the torsional stiffness of the CPF group was significantly $(p<$ $0.0001)$ greater than that of the UEF group by 1.31. The stiffness value of the EPF group was also significantly $(p<$ 0.0001 ) greater than that of the UEF group by 1 .

\section{Construct strength}

For axial compression, the strength of the CPF group $(2792.2 \mathrm{~N})$ was significantly $(p<0.0001)$ higher than that of the UEF group $(1769.0 \mathrm{~N})$ by 0.58 . The axial parameter of the EPF group $(2560.5 \mathrm{~N})$ was also significantly $(p<0.0001)$ greater than that of the UEF group by 0.45 . The results are displayed in Fig. 5a. Both CPF and EPF constructs failed by catastrophic fracture of the diaphysis through the screw hole (Fig. 6a). After fracture, the CPF constructs in four specimens displayed no implant hardware failure, screw breakage occurred in one specimen, and screw bending occurred in one specimen. Among the EPF constructs, no implant hardware failure was found in one specimen, screw and plate bending were observed in three specimens, and screw breakage occurred in two specimens. The UEF constructs failed as a result of nonrecoverable fracture gap closure due to half-pin and rod bending in five specimens and due to fracture of the diaphysis in one specimen.

In four-point bending, the construct strength of the CPF group $(58.2 \mathrm{Nm})$ was significantly $(p<0.0001)$ greater than that of the UEF group $(47.9 \mathrm{Nm})$ by $22 \%$. The strength value of the EPF group $(56.4 \mathrm{Nm})$ was also significantly $(p<0.0001)$ higher than that of the UEF group by $18 \%$. A chart of these results is shown in Fig. 5b. All constructs failed by catastrophic fracture of the diaphysis (Fig. 6b). After fracture, none of the CPF constructs displayed implant hardware failure; the EPF constructs showed no implant hardware failure in three specimens and screw bending in three specimens; and the UEF constructs showed half-pin and rod bending in four specimens and half-pin breakage and rod bending fracture in two specimens.

For torsion, the strength of the CPF group (34.2 $\mathrm{Nm})$ was significantly $(p<0.0001)$ greater than that of the UEF group $(24.2 \mathrm{Nm})$ by 0.41 . The strength value of the EPF group $(30.0 \mathrm{Nm})$ was also significantly $(p<0.0001)$ greater than that of the UEF group by 0.24 . The results are displayed in Fig. 5c. The CPF constructs failed by screw and plate bending in four specimens, screw breakage in one specimen and spiral fracture in one specimen. The EPF constructs failed as a result of screw and plate bending in two specimens, screw breakage and plate bending in two specimens and spiral fracture in two specimens. The UEF constructs exhibited oblique fracture in four specimens (Fig. 6c) and half-pin and rod bending in two specimens, resulting in nonrecoverable deformation in the region of fracture.

Table 1 Mean age and T-score for three fixation configurations

\begin{tabular}{llll}
\hline Construct & Number & Age (years) & T-score \\
& & Mean \pm SD & Mean \pm SD \\
\hline Classical plate-type external fixator & 18 & $33.0 \pm 9.6$ & $-0.81 \pm 0.09$ \\
Extended plate-type external fixator & 18 & $31.0 \pm 10.9$ & $-0.84 \pm 0.10$ \\
Unilateral external fixator & 18 & $35.5 \pm 9.2$ & $-0.83 \pm 0.09$ \\
\hline
\end{tabular}


a

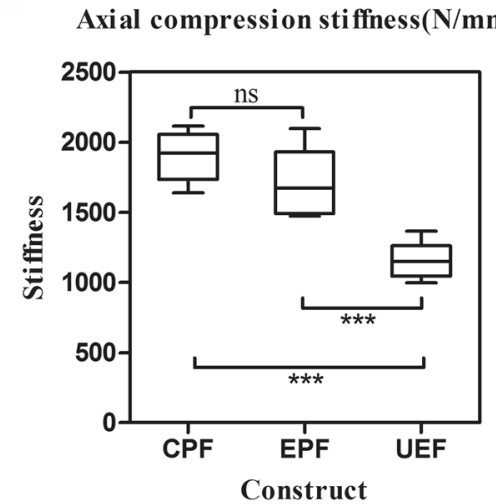

b

Four-point bending stiffiness( $\mathrm{Nm} / \mathrm{deg})$

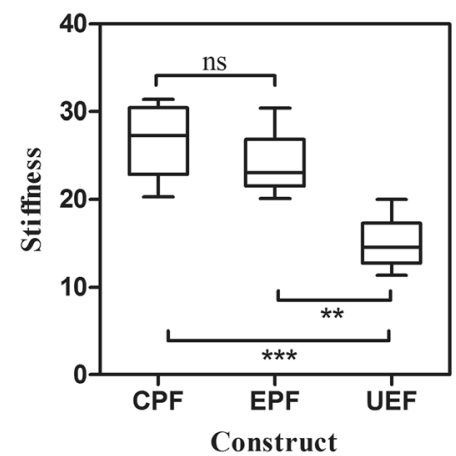

c

Torsional stiffiness( $\mathrm{Nm} / \mathrm{deg})$

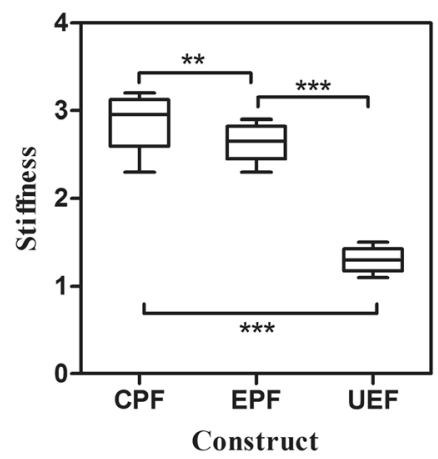

Fig. 4 Box plots of the three fixation configurations under axial compression (a), four-point bending (b) and torsion (c). CPF, classical plate-type external fixator; EPF, extended plate-type external fixator; UEF, unilateral external fixator. ${ }^{* *}$ indicates statistical significance $(p<0.01)$; ${ }^{* *}$ indicates statistical significance $(p<0.001)$; ns indicates no significant difference

\section{Discussion}

The results of this study support the hypothesis that the plate-type external fixator can remarkably increase the stiffness of the fracture fixation construct while retaining sufficient strength. In this experiment, the two configurations employing the plate-type external fixator exhibited higher stiffness and strength than the traditional UEF in axial compression, four-point bending and torsion. Furthermore, our study showed that the stiffness and strength of the construct would decrease with thinner plate thicknesses. However, the extended plate-type external fixator was still stiffer and stronger than that of the traditional UEF.

\section{Construct stiffness}

The stiffness of external fixators reported in previous literatures has ranged from $50 \mathrm{~N} / \mathrm{mm}$ to $2500 \mathrm{~N} / \mathrm{mm}$ in axial compression, $10 \mathrm{Nm} / \mathrm{deg}$ to $100 \mathrm{Nm} / \mathrm{deg}$ in fourpoint bending, and $1 \mathrm{Nm} / \mathrm{deg}$ to $4 \mathrm{Nm} / \mathrm{deg}$ in torsion, respectively [4, 6, 28-31]. The stiffness values of all of the bone-implant constructs in our study research were within these ranges, and the plate-type external fixator provided remarkably higher torsional stiffness than the UEF. The highest stiffness was achieved in the fracture model with an offset distance of $5 \mathrm{~mm}$, while the lowest stiffness was achieved with distances up to $30 \mathrm{~mm}$. Our study reveals the possibility that stiffness may decrease with increasing offset.

\section{Construct strength and failure mode}

According to our study, we conclude that the plate-type external fixator is stronger than the UEF, thus contributing to more durable fixation to allow progressive functional training of greater intensity and duration. $\mathbf{a}$ Axial compression strength(N)

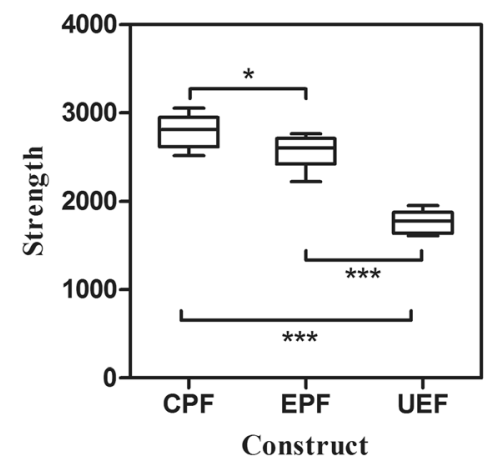

b Four-point bending strength( $\mathrm{Nm})$

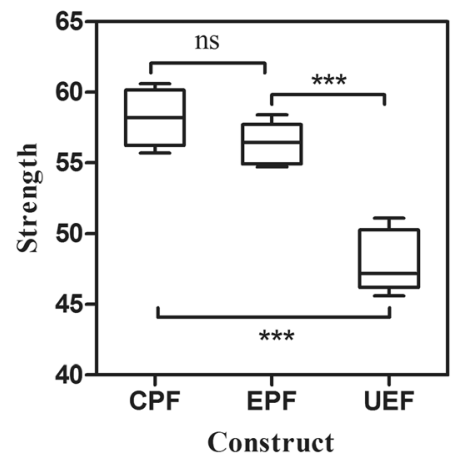

c
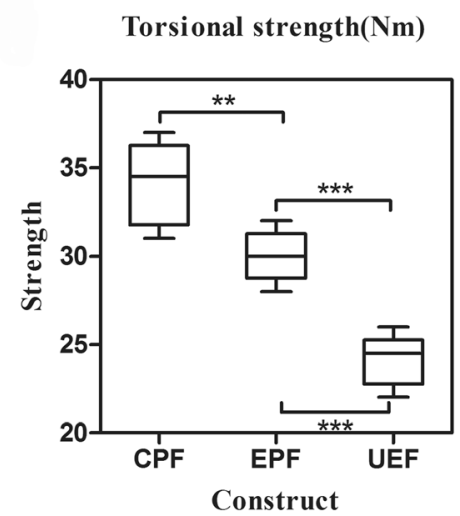

Fig. 5 Box plots of the three fixation configurations under axial compression (a), four-point bending (b) and torsion (c). CPF, classical plate-type external fixator; EPF, extended plate-type external fixator; UEF, unilateral external fixator. ${ }^{*}$ indicates statistical significance $(p<0.05)$; ${ }^{* *}$ indicates statistical significance $(p<0.01)$; ${ }^{* *}$ indicates statistical significance $(p<0.001)$; ns indicates no significant difference 


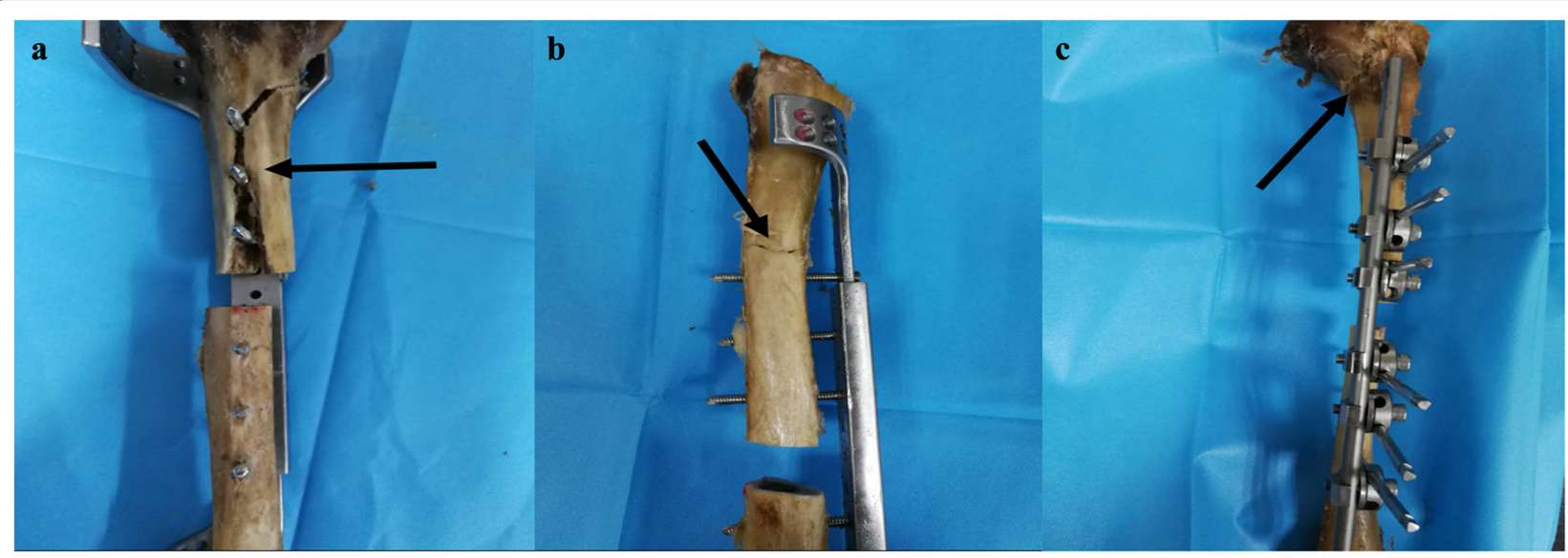

Fig. 6 Photographs of the failure modes of configurations for a axial compression, catastrophic fracture of the diaphysis through the screw hole found in the classical plate-type external fixator group (indicated by the black arrow); $\mathbf{b}$ four-point bending, catastrophic fracture of the diaphysis found in the extended plate-type external fixator group (indicated by the black arrow); and $\mathbf{c}$ torsion, oblique fracture found in the unilateral external fixator group (indicated by the black arrow)

Moreover, for progressive dynamic loading to failure, the UEF group displayed the greatest implant hardware failure and the minimum peak load.

\section{Factors infecting the stiffness and strength}

Previous studies that have investigated how fixation stiffness and strength can be influenced have shown that several factors affect the stability and durability of boneimplant constructs $[19,29,32-37]$. The working length, defined as the distance between the first two screws on both sides of the fracture gap, has a marked impact on biomechanical fixation. Meanwhile, altering the offset distance between the plate and the bone surface can significantly change the stability and durability of the boneimplant construct. Moreover, the number and positions of the screws, the fracture gap size, and the material properties of the external fixator all influence the biomechanical parameters. In our study, the working length of the three fixation groups was set to $60 \mathrm{~mm}$, namely, fourfold the hole spacing. A $15 \mathrm{~mm}$ offset was maintained between the plate/rod and the bone surface in the three fixation groups. In addition, the number of screws, the fracture gap size, and the material properties were the same in the three external fixation groups. Therefore, it can be concluded that the plate-type external fixator provides more sufficient stability and durability than the UEF because the stiffness and strength of the plate-type external fixator were higher in axial compression, four-point bending and torsion.

\section{Implications of the novel fixator}

The plate-type external fixator described herein by our research group is the first such prototype to be described worldwide. These tests represent the first biomechanical study comparing the stiffness and strength of the novel fixator with the UEF. In addition to the higher stiffness and strength and the lower profile, the plate-type external fixator, which is designed to match perfectly with the crus, provides sufficient skin distance by allowing the distance between the bone surface and the external plate to be adjusted. In addition, the length of the novel fixator can be adjusted for people of different heights. When applying the novel fixator to treat tibial fractures without an open approach, we need to make closed reduction a priority; if unsuccessful, limited exposure is needed.

\section{The angle-stabilizing property}

The locking plate, which is based on an angle-stabilizing property, is used as an external fixator and can be considered as a promising and satisfactory procedure, which has already been reported in many literatures $[1,2,38$, 39]. The plate-type external fixator, also depending on the angle-stabilizing property, is expected to yield excellent clinical results when used for treating tibia fracture.

\section{Limitations}

There remain several limitations of this study. First, the investigation of stiffness and strength was performed in vitro, and all specimens were cleaned of any soft tissues; therefore, in the load applied in this fixation model may not completely stimulate the multifaceted load pattern in vivo. Second, the fixation parameters were only investigated for nonosteoporotic specimens. Ideally, we the biomechanical parameters for osteoporotic specimens should also be investigated, since stiffness and strength are highly affected by bone quality.

\section{Feasibility and practicality}

Despite the aforementioned limitations, we believe that the model used in this study is appropriate for 
comparing stiffness and strength between the plate-type external fixator and the UEF. The biomechanical parameters were investigated individually for the main load bearings that a fracture-fixator configuration might sustain, namely, axial compression loading, bending loading and torsional loading. These parameters are extremely useful for developing a comprehensive understanding of the relative benefits of plate-type external constructs under in vivo multifaceted loading modes, which comprise some of the combinations of forces investigated herein. Therefore, we believe that the results of this study are appropriate for extrapolation to human applications and can be applied to make clinical judgments.

\section{Conclusions}

The design of an external fixator with optimal biomechanical function and a low profile has been a research priority. In this study, we found that the was significantly stiffer and stronger than the traditional UEF, and the stiffness of plate-type external fixator was closer to the optimal value. Moreover, the low profile of the platetype external fixator reduces inconvenience during dressing and ambulation, thus increasing comfort and improving its acceptance among patients. In conclusion, the plate-type external fixator provides a promising and satisfactory alternative to the traditional UEF, since its sufficient stiffness and strength and lower profile.

\section{Abbreviations}

ANOVA: Analysis of variance; CPF: Classical plate-type external fixator; EPF: Extended plate-type external fixator; UEF: Unilateral external fixator

\section{Acknowledgements}

We thank Huimin Li, PHD, for her support with the laboratory tests. We also thank Kailiang Zhang, MD, for his valuable assistance in processing the picture.

\section{Authors' contributions}

DS: modeling, mechanical testing, data analysis and manuscript writing. KL: data collection, mechanical testing and photograph processing. $\mathrm{HZ}$ : modeling, statistical process and photograph processing. XW: data collection and photograph processing. GL: statistical analysis and modeling. LZ: study design and final approval of the manuscript. All authors have read and approved the final manuscript.

\section{Funding}

This work was supported by the Second Affiliated Hospital of Air Force Medical University, Xi'an, Shaanxi, China [grant number 2014JSYJ001].

\section{Availability of data and materials}

All data supporting the results of this study are available within the article.

\section{Ethics approval and consent to participate}

All experiments were approved by the Ethical Committee of the Second Affiliated Hospital of Air Force Medical University and carried out according to the corresponding principles and ethical standards. Moreover, the cadavers consented to donate their body to our institute for research purposes.

\section{Consent for publication}

Not applicable.

\section{Competing interests}

The authors declare that they have no competing interests.

\section{Author details}

'Department of Orthopedics, the Second Affiliated Hospital of Air Force Medical University, Xi'an 710038, Shaanxi, China. ${ }^{2}$ State Key Laboratory for Strength and Vibration of Mechanical Structures, School of Aerospace Engineering, Xi'an Jiaotong University, Xi'an 710049, Shaanxi, China.

Received: 18 September 2019 Accepted: 17 February 2020

Published online: 27 February 2020

\section{References}

1. Ma C, Wu C, Jiang J, Tu Y, Lin T. Metaphyseal locking plate as an external fixator for open tibial fracture: clinical outcomes and biomechanical assessment. Injury. 2017;48(2):501-5.

2. Qiu X, Yuan H, Zheng X, Wang J, Xiong J, Chen Y. Locking plate as a definitive external fixator for treating tibial fractures with compromised soft tissue envelop. Arch Orthop Trauma Surg. 2014;134(3):383-8.

3. Luo P, Xu D, Wu J, Chen Y. Locked plating as an external fixator in treating tibial fractures. Medicine. 2017;96(49):e9083.

4. Ang BFH, Chen JY, Yew AKS, Chua SK, Chou SM, Chia SL, et al. Externalised locking compression plate as an alternative to the unilateral external fixator: a biomechanical comparative study of axial and torsional stiffness. Bone Joint Res. 2017;6(4):216-23.

5. Bottlang M, Doornink J, Fitzpatrick DC, Madey SM. Far cortical locking can reduce stiffness of locked plating constructs while retaining construct strength. J Bone Joint Surg (Am Vol). 2009;91(8):1985-94.

6. Epari DR. Timely fracture-healing requires optimization of axial fixation stability. J Bone Joint Surg Am. 2007:89(7):1575.

7. Button $G$, Wolinsky P, Hak D. Failure of less invasive stabilization system plates in the distal femur: a report of four cases. J Orthop Trauma. 2004; 18(8):565-70.

8. Sommer C, Gautier E, Müller M, Helfet DL, Wagner M. First clinical results of the locking compression plate (LCP). Injury. 2003;34:43-54.

9. Zderic I, Oh J, Stoffel K, Sommer C, Helfen T, Camino G, et al. Biomechanical analysis of the proximal femoral locking compression plate: do quality of reduction and screw orientation influence construct stability? J Orthop Trauma. 2018:32(2):67-74.

10. Bottlang M, Doornink J, Lujan TJ, Fitzpatrick DC, Marsh JL, Augat P, et al. Effects of construct stiffness on healing of fractures stabilized with locking plates. J Bone Joint Surg (Am Vol). 2010;92(Suppl 2):12-22.

11. Hohloch L, Konstantinidis L, Wagner FC, Strohm PC, Südkamp And NP, Reising K. Biomechanical evaluation of a new technique for external fixation of unstable supracondylar humerus fractures in children. Technol Health Care. 2015;23(4):453-61.

12. Tulner SA, Strackee SD, Kloen P. Metaphyseal locking compression plate as an external fixator for the distal tibia. Int Orthop. 2012;36(9):1923-7.

13. Apivatthakakul T, Sananpanich K. The locking compression plate as an external fixator for bone transport in the treatment of a large distal tibial defect: a case report. Injury. 2007;38(11):1318-25.

14. Feng W, Fu L, Liu J, Qi X, Li D, Yang C. Biomechanical evaluation of various fixation methods for proximal extra-articular tibial fractures. J Surg Res. 2012; 178(2):722-7.

15. Sirisreetreerux N, Sa-Ngasoongsong P, Chanplakorn P, Kulachote N, Laohajaroensombat S, Suphachatwong C, et al. Using a reconstruction locking compression plate as external fixator in infected open clavicle fracture. Orthop Rev (Pavia). 2013;5(2):52-5.

16. Xu GH, Liu B, Zhang Q, Wang J, Chen W, Liu YJ, et al. Biomechanical comparison of gourd-shaped LCP versus LCP for fixation of comminuted tibial shaft fracture. J Huazhong Univ Sci Technolog Med Sci. 2013;33(2): 250-7.

17. Zhang J, Ebraheim N, Li M, He X, Liu J, Zhu L, et al. External fixation using femoral less invasive stabilization system plate in Tibial proximal Metaphyseal fracture. Clin Orthop Surg. 2015;7(1):8.

18. Younger ASE, Morrison J, Mackenzie WG. Biomechanics of external fixation and limb lengthening. Foot Ankle Clin. 2004;9(3):433-48.

19. Stoffel K, Dieter U, Stachowiak G, Gächter A, Kuster MS. Biomechanical testing of the LCP - how can stability in locked internal fixators be controlled? Injury. 2003;34:11-9. 
20. Miller DL, Goswami T. A review of locking compression plate biomechanics and their advantages as internal fixators in fracture healing. Clin Biomech. 2007;22(10):1049-62.

21. Fitzpatrick DC, Doornink J, Madey SM, Bottlang M. Relative stability of conventional and locked plating fixation in a model of the osteoporotic femoral diaphysis. Clin Biomech. 2009;24(2):203-9.

22. Sun $H, H e$ Q, Zhang B, Zhu Y, Zhang W, Chai Y. A biomechanical evaluation of different fixation strategies for posterolateral fragments in tibial plateau fractures and introduction of the 'magic screw'. Knee. 2018;25(3):417-26.

23. Gosling T, Schandelmaier P, Marti A, Hufner T, Partenheimer A, Krettek C. Less invasive stabilization of complex tibial plateau fractures: a biomechanical evaluation of a unilateral locked screw plate and double plating. J Orthop Trauma. 2004;18(8):546-51.

24. Hasenboehler E, Smith WR, Laudicina L, Philips GC, Stahel PF, Morgan SJ. Fatigue behavior of llizarov frame versus tibial interlocking nail in a comminuted tibial fracture model: a biomechanical study. J Orthop Surg Res. 2006;1(1):16.

25. Walpole SC, Prieto-Merino D, Edwards P, Cleland J, Stevens G, Roberts I. The weight of nations: an estimation of adult human biomass. BMC Public Health. 2012;12:439.

26. Oh J, Sahu D, Ahn Y, Lee S, Tsutsumi S, Hwang J, et al. Effect of fracture gap on stability of compression plate fixation: A finite element study. J Orthop Res. 2009;28(4):462-7.

27. Sellei RM, Kobbe P, Dadgar A, Pfeifer R, Behrens $M$, von Oldenburg G, et al. External fixation design evolution enhances biomechanical frame performance. Injury. 2015;46(Suppl 3):S23-6.

28. Liu W, Yang L, Kong X, An L, Hong G, Guo Z, et al. Stiffness of the locking compression plate as an external fixator for treating distal tibial fractures: a biomechanics study. BMC Musculoskelet Disord. 2017;18(1):26

29. Stoffel K, Lorenz KU, Kuster MS. Biomechanical considerations in plate osteosynthesis: the effect of plate-to-bone compression with and without angular screw stability. J Orthop Trauma. 2007;21(6):362-8.

30. Schmidt U, Penzkofer R, Bachmaier S, Augat P. Implant material and design Alter construct stiffness in distal femur locking plate fixation: a pilot study. Clin Orthop Relat R. 2013;471(9):2808-14.

31. Windolf M, Klos K, Wähnert D, van der Pol B, Radtke R, Schwieger K, et al. Biomechanical investigation of an alternative concept to angular stable plating using conventional fixation hardware. BMC Musculoskelet Disord. 2010;11(1):95.

32. Kenwright J, Gardner T. Mechanical influences on tibial fracture healing. Clin Orthop Relat Res. 1998;355S:S179-90.

33. Ahmad M, Nanda R, Bajwa AS, Candal-Couto J, Green S, Hui AC. Biomechanical testing of the locking compression plate: when does the distance between bone and implant significantly reduce construct stability? Injury. 2007;38(3):358-64.

34. Bible JE, Mir HR. External fixation: principles and applications. J Am Acad Orthop Sur. 2015;23(11):683-90.

35. Märdian S, Schaser K, Duda GN, Heyland M. Working length of locking plates determines interfragmentary movement in distal femur fractures under physiological loading. Clin Biomech. 2015:30(4):391-6.

36. Ya Ish FMM, Nanu AM, Cross AT. Can DCP and LCP plates generate more compression? The effect of multiple eccentrically placed screws and their drill positioning guides. Injury. 2011;42(10):1095-100.

37. Yang JC, Lin K, Wei H, Chen W, Chiang C, Chang M, et al. Importance of a moderate plate-to-bone distance for the functioning of the far cortical locking system. Med Eng Phys. 2018;56:48-53.

38. Ma C, Tu Y, Yeh J, Yang S, Wu C. Using external and internal locking plates in a two-stage protocol for treatment of segmental Tibial fractures. $J$ Trauma. 2011:71(3):614-9.

39. Kloen P. Supercutaneous plating: use of a locking compression plate as an external fixator. J Orthop Trauma. 2009;23(1):72-5.

\section{Publisher's Note}

Springer Nature remains neutral with regard to jurisdictional claims in published maps and institutional affiliations.

\section{Ready to submit your research? Choose BMC and benefit from:}

- fast, convenient online submission

- thorough peer review by experienced researchers in your field

- rapid publication on acceptance

- support for research data, including large and complex data types

- gold Open Access which fosters wider collaboration and increased citations

- maximum visibility for your research: over $100 \mathrm{M}$ website views per year

At $\mathrm{BMC}$, research is always in progress.

Learn more biomedcentral.com/submissions 